\title{
Análise de comportamento térmico de HIS térreas unifamiliares em Santa Maria, RS
}

Analysis of the thermal behaviour of one-floor, singlefamily social housing units in Santa Maria, RS, Brazil

\section{Giane de Campos Grigoletti Gabriela Inês Linck}

\section{Resumo}

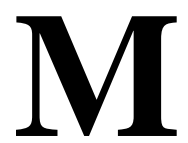

uitos estudos sobre habitação para a população de baixa renda têm sido desenvolvidos recentemente, apontando problemas similares em distintos países. A adoção de soluções não adequadas ao clima é uma causa para o baixo desempenho térmico. Este artigo apresenta uma análise de desempenho térmico de habitações de interesse social (HIS) construídas na Zona Bioclimática 2, sul do Brasil, pelo levantamento da satisfação de usuários. O desempenho térmico foi determinado por coeficientes globais de ganhos e perdas de calor, condensação sobre superfícies internas e assimetria da radiação térmica. A satisfação foi apurada com a aplicação de questionários, duas vezes por semana, em janeiro, fevereiro e julho de 2012 , pela escala de valores proposta pela ISO 7730. Quando da aplicação dos questionários, foram medidas simultaneamente as temperaturas interna e externa das habitações. Verificaram-se o baixo desempenho térmico e a inadequação do envelope da edificação ao clima. A cobertura é o elemento que mais contribui para o baixo desempenho térmico. Os usuários consideraram suas casas mais desconfortáveis no verão, revelando maior tolerância ao frio. Durante as entrevistas, temperaturas da ordem de $39^{\circ} \mathrm{C}$ no verão e de $8^{\circ} \mathrm{C}$ no inverno foram registradas no interior das habitações no momento das entrevistas.

Palavras-chave: HIS. Desempenho térmico. Conforto térmico.

\begin{abstract}
Many studies focused on low-cost housing have been developed in recent years, pointing out similar problems in different countries. The adoption of solutions that are unsuited to the local climate leads to poor thermal performance. This paper presents a study of the thermal performance and occupants' thermal sensation in low-cost housing in southern Brazil through an analysis of users' satisfaction. Thermal performance was determined by inner surface condensation, global flow heat coefficients, and radiant asymmetry. The perceived thermal sensation was analysed according to the ISO 7730. Questionnaires were applied twice a week during January, February and July 2012. During the application of the questionnaires, indoor and outdoor temperatures were measured in order to compare with the occupants' opinions. The results indicate poor thermal performance of the building and inadequacy of the building envelope to the local climate. The roofs were the feature that most contributed to the poor thermal performance of the building. Users considered their houses most uncomfortable in the summer, showing greater tolerance to cold. During the interviews, high (39 $\left.{ }^{\circ} \mathrm{C}\right)$ and low $\left(8^{\circ} \mathrm{C}\right)$ indoor air temperatures were registered, revealing poor indoor thermal conditions.
\end{abstract}

Recebido em 03/01/14

Aceito em 31/03/14 Keywords: Low-cost housing. Thermal performance. Thermal comfort. Giane de Campos Grigoletti
Universidade Federal de Santa Maria Santa Maria - RS - Brasil

Gabriela Inês Linck Universidade Federal de Santa Maria Santa Maria - RS - Brasil 


\section{Introdução}

O tema habitação de interesse social (HIS) desperta interesse em vários países, principalmente em países subdesenvolvidos ou em desenvolvimento. Entre outros problemas, o mau desempenho térmico é recorrente, levando a situações em que as condições ambientais são melhores no meio externo do que no interior da edificação. A avaliação de habitações já construídas e em uso pode contribuir para o desenvolvimento de soluções mais adequadas ao clima e ao público-alvo.

Estudos em outros países apontam problemas similares aos verificados no Brasil. Na Argentina, Mercado, Esteves e Fillipín (2010) analisaram o comportamento térmico de HIS. A pesquisa revelou péssimas condições térmicas e um envelope não adequado ao clima. Segundo os autores, soluções simples poderiam incrementar o desempenho térmico, como a ventilação no verão e a proteção externa das janelas durante a noite no inverno. López et al. (2012), no México, mediram temperatura do ar e umidade do ar em HIS para determinar a adaptação dos usuários a condições ambientais internas da edificação e aplicaram questionários durante duas semanas. Os resultados apontaram que os hábitos dos usuários são importantes para garantir seu conforto térmico, tais como o abrir e fechar janelas e vestir roupas apropriadas à estação. Rabelo, Tafra e Palma (2012), no Chile, avaliaram conforto térmico, ventilação, umidade interna e pontes térmicas de um protótipo de HIS. O método envolveu medições in loco e simulações computacionais. A avaliação apontou o mau desempenho térmico do protótipo tanto para condição de frio quanto de calor, condensação sobre superfícies e excessiva infiltração de ar no inverno. No verão, a falta de ático ventilado na cobertura e uma orientação solar desfavorável promoveram o superaquecimento da edificação. Gomez et al. (2011) realizaram estudo da sensação térmica percebida por moradores de HIS e habitações autoconstruídas no México por meio de questionário baseado na ISO 10551. A avaliação mostrou maior tolerância e melhor adaptação térmica para as condições da habitação autoconstruída, mesmo que esta apresente temperatura do ar e umidade relativa mais altas do que a habitação econômica.

No Brasil, existem normas específicas que tratam do desempenho geral de edificações de uso residencial (ASSOCIAÇÃO..., 2005, 2013), porém ainda se verifica sua má qualidade, e o esforço para sua melhoria ainda é premente, fato demonstrado por diversas pesquisas sobre o tema. Krüger e Dumke (2001) avaliaram diferentes sistemas construtivos, analisando a energia consumida, o desempenho térmico na situação de verão e inverno e a sensação subjetiva de conforto térmico dos moradores por meio de questionários, para um dia de verão e outro de inverno, comparando esses dados com as condições internas de temperatura e umidade. $\mathrm{O}$ questionário foi elaborado conforme $\mathrm{o}$ voto médio estimado (PMV). Os resultados da pesquisa expressam uma predisposição dos entrevistados a temperaturas mais frias, característica predominante na região. Sacht e Rossignolo (2008) avaliaram, por simulação computacional, o desempenho térmico de duas HIS construídas com diferentes tipos de alvenaria para oito zonas bioclimáticas brasileiras, conforme a NBR 15220 (ASSOCIAÇÃO..., 2005). A cobertura era composta de telha cerâmica sem forro. Para o dia crítico de inverno, a habitação, independentemente do tipo de envoltória, satisfez o nível mínimo exigido pela norma para algumas cidades, como Ponta Grossa, São Carlos e Brasília. O projeto de habitação simulado para a cidade de São Paulo apenas satisfez a norma para alvenaria em blocos de concreto. Para as cidades de Teresina, Presidente Prudente, Belém, Caxias do Sul, Florianópolis e Santos, nenhuma envoltória satisfez o desempenho mínimo. Os autores consideram que esse desempenho inferior é resultado da baixa resistência térmica da cobertura Grigoletti, Rotta e Müller (2011) avaliaram quatro HIS em Santa Maria, duas em blocos cerâmicos, cobertura em fibrocimento e laje de concreto, e duas em blocos de concreto, cobertura de fibrocimento e forro de madeira, por meio de medições in loco de temperatura do ar interno e externo (medida junto à edificação) e levantamento da opinião de seus usuários, durante a primeira quinzena do mês de março. Registradores contínuos foram instalados na sala-cozinha e no dormitório principal. As habitações em blocos cerâmicos apresentaram melhor desempenho medido do que as de concreto. Para um mesmo sistema construtivo, cômodos com janelas voltadas entre os quadrantes nordeste e sudoeste alcançaram temperaturas próximas aos $35^{\circ} \mathrm{C}$. As temperaturas internas mantiveram-se próximas das máximas registradas externamente. Os usuários mostraramse insatisfeitos com as condições de calor.

Grigoletti e Sattler (2010) propuseram um método de avaliação de desempenho higrotérmico de HIS baseado em parâmetros que expressam o comportamento global da edificação, não somente de paredes e cobertura, como a NBR 15220 e NBR 15575 (ASSOCIAÇÃO..., 2005, 2013). O estudo deu origem a dezessete parâmetros e a três classificações possíveis, de acordo com referências

110 Grigoletti, G. de C.; Linck, G. I 
implantadas e propostas para a realidade de Porto Alegre, RS, permitindo que novas soluções possam ser avaliadas de acordo com essas referências.

Este artigo tem por objetivo avaliar o desempenho térmico e a sensação térmica expressa pelos usuários de cinco tipos de HIS construídas em Santa Maria, RS (Zona Bioclimática 2), propondo configurações gerais para HIS condizentes com o clima local.

\section{Método de pesquisa}

O método de pesquisa baseia-se nas normas NBR 15220 (ASSOCIAÇÃO..., 2005), estudos relativos a parâmetros térmicos para avaliação global de desempenho térmico de HIS (GRIGOLETTI; SATTLER, 2010) e estudos que avaliam o conforto térmico através da opinião de usuários e do levantamento de seus hábitos para adaptar o microclima a suas necessidades térmicas (KRÜGER; DUMKE，2001; GOMES， 2003; GOMEZ et al., 2011), na ISO 7730 (INTERNATIONAL..., 1994) e ASHRAE (AMERICAN..., 2004).

Cinco tipos de HIS unifamiliares térreas (duas soluções em planta) com orientações solares diferentes foram selecionadas. Essas habitações foram construídas em períodos diferentes, segundo políticas habitacionais distintas, a saber, na década de $1980\left(\mathrm{TN}^{1}\right)$, inauguradas em $2010\left(\mathrm{CR}^{2}\right)$ e em $2012\left(\mathrm{ZA}^{3}\right)$. O Quadro 1 ilustra as habitações e descreve suas principais características.

\section{Análise do desempenho higrotérmico}

Para a análise global de desempenho térmico foram selecionadas nove unidades, uma $\mathrm{TN}$, quatro CR (diferindo na orientação solar) e quatro ZA (diferindo na orientação solar), que não sofreram alterações pelos usuários. A orientação solar refere-se à orientação da fachada frontal. As condições de contorno para realizar os cálculos dos parâmetros térmicos foram consideradas iguais à de Porto Alegre, cidade cujas normais climatológicas são similares às de Santa Maria, uma vez que não existem dados sistematizados para o projeto de edificações disponíveis para o município. O Quadro 2 apresenta essas condições.

A resistência térmica total, $\mathrm{R}_{\mathrm{T}}$, a transmitância térmica, $\mathrm{U}$, o fator solar, $\mathrm{FS}_{\mathrm{o}}$, e o atraso térmico, $\varphi$, foram calculados de acordo com a NBR 15220 (ABNT, 2005).

\footnotetext{
${ }^{1}$ Cohab Tancredo Neves.

${ }^{2}$ Residencial Cipriano da Rocha.

${ }^{3}$ Residencial Zilda Arns.
}

O coeficiente de amortecimento foi calculado a partir da Equação 1, onde Rt é a resistência térmica de face a face do elemento (parede, cobertura, porta, janela), e B1 e B2 são determinados através da NBR 15220 (ASSOCIAÇÃO..., 2005).

$\mu=e^{-0,130 \% \times R_{t} \times \sqrt{B 1+B 2}}$

Eq. 1

O coeficiente volumétrico global de perdas de calor, $\mathrm{GV}_{\text {inverno, }}$ foi calculado através da Equação 2 (GIVONI, 1981). Onde $\mathrm{Q}_{\mathrm{T}}$ é o fluxo de calor através dos fechamentos; $V$ é o volume interior das casas; e $t_{e}$ e $t_{i}$ são as temperaturas externas e internas respectivamente. No cálculo do $G_{\text {inverno }}$ são consideradas perdas devidas a infiltrações de ar por esquadrias e frestas de coberturas.

$$
G V_{\text {inverno }}=\frac{Q_{T}}{V\left(t_{e}-t_{i}\right)}
$$

Eq. 2

O coeficiente volumétrico de ganhos de calor,


expressão, porém $\mathrm{Q}_{\mathrm{T}}$ corresponde ao fluxo de calor para $\mathrm{T}_{\text {ar-sol }}$ máximo. $\mathrm{GV}_{\text {inverno }}$ e $\mathrm{GV}_{\text {verão }}$ devem ser menores do que 4,0 W/(m $\left.\mathrm{m}^{3} \mathrm{~K}\right)$ e $18,0 \mathrm{~W} /\left(\mathrm{m}^{3} \mathrm{~K}\right)$ respectivamente (GRIGOLETTI; SATTLER, 2010).

A análise da condensação sobre superfícies internas baseou-se no fluxo de calor em regime estacionário através de paredes e cobertura à noite para condições de inverno. As temperaturas superficiais internas foram calculadas para condições de temperatura do ar interno de $18^{\circ} \mathrm{C}$, temperatura externa de $7,5^{\circ} \mathrm{C}$ e umidade relativa do ar de 95\% (AROZTEGUI; BRIZOLARA, 1980).

A assimetria da radiação térmica é a diferença entre temperaturas radiantes planas, $\mathrm{T}_{\mathrm{rp}}$, sobre lados opostos de um elemento plano infinitesimal (INTERNATIONAL..., 1996). Esse parâmetro é importante para condições de conforto, pois a assimetria térmica é percebida pelos indivíduos quando ela é muito elevada. A temperatura radiante plana pode ser calculada pela Equação 3, onde $\mathrm{t}_{\mathrm{si}}$ são as temperaturas das superfícies no campo de visão de um dos lados da placa infinitesimal e $f_{i}$ são os fatores de forma das superfícies citadas.

$T_{r p}=\sum_{i}\left(t_{s i} \times f_{i}\right)$

Eq. 3

$\mathrm{T}_{\mathrm{rp}}$ é calculada para cada um dos lados da placa plana infinitesimal, e encontrada sua diferença. Para condições de inverno, a análise deve considerar as salas com superfícies mais frias, tais como ambientes com grandes áreas envidraçadas, principalmente janelas sem elementos de fechamento opaco. Para o verão, a análise deve ser 
feita para salas voltadas a oeste, noroeste e sudoeste, pois esses ambientes recebem elevada carga térmica devido à insolação. Também a cobertura deve ser analisada tanto para inverno quanto para verão. Os valores de $9{ }^{\circ} \mathrm{C}$ (cobertura) e $14{ }^{\circ} \mathrm{C}$ (paredes) são as referências para a máxima assimetria de radiação térmica (INTERNATIONAL..., 1996).
Além dos parâmetros térmicos citados, ático da cobertura ventilado somente no verão, possibilidade de ventilação noturna (venezianas nas janelas) no verão e janelas voltadas a norte para aquecimento solar passivo também foram analisados.

\section{Quadro 1 - Habitações selecionadas para avaliação do desempenho térmico}

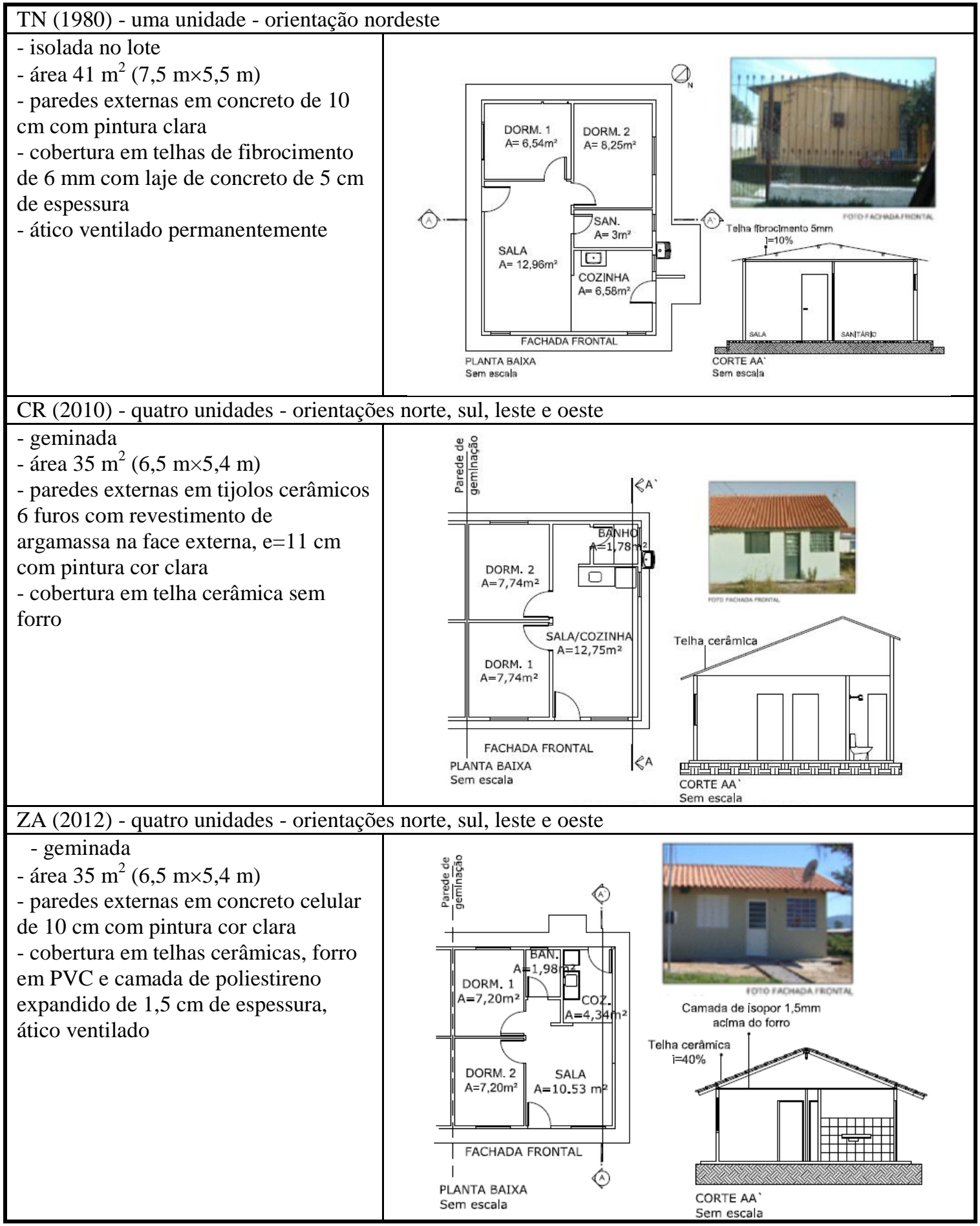


Quadro 2 - Condições de cálculo dos parâmetros térmicos

\begin{tabular}{|l|l|}
\hline Inverno & Verão \\
\hline Temperatura do ar externo $=7,5^{\circ} \mathrm{C}$ & Temperatura do ar externo $=33,5^{\circ} \mathrm{C}$ \\
Amplitude térmica $=10^{\circ} \mathrm{C}$ & Temperatura mínima do ar externo $=23,0{ }^{\circ} \mathrm{C}$ \\
Umidade relativa do ar $=95,0 \%$ & Umidade relativa do ar $=72,0 \%$ \\
Temperatura do ar interno $=18,0^{\circ} \mathrm{C}$ & Temperatura do ar interno $=29,0{ }^{\circ} \mathrm{C}$ \\
\hline
\end{tabular}

Fonte: Aroztegui e Brizolara (1980).

\section{Opinião de usuários}

A opinião de usuários das habitações foi obtida quanto a sua sensação térmica percebida, seus hábitos em relação à adaptação a suas necessidades térmicas e quanto a sua percepção do desempenho térmico. Devido a atrasos na obra do ZA, este residencial não foi submetido ao levantamento da sensação térmica percebida. Para a escolha das unidades, foi realizado um levantamento acerca do número de habitações ainda originais (conforme projeto arquitetônico fornecido pela Prefeitura Municipal) e escolhidas 5\% destas. Dessa forma, o público-alvo da pesquisa constituiu-se de 16 pessoas (1 por habitação) do $\mathrm{CR}$ e apenas 1 morador da TN (foram encontradas apenas duas habitações ainda originais para essa tipologia, porém um dos proprietários não aceitou participar da pesquisa).

As habitações escolhidas para aplicar os questionários apresentam a mesma tipologia das habitações submetidas à análise de desempenho. Selecionaram-se, no CR, além de habitações com as mesmas orientações solares daquelas submetidas ao método de avaliação, suas habitações geminadas. O objetivo dessa escolha foi verificar se havia alteração na percepção e opinião dos moradores das duas habitações de uma edificação geminada, já que a orientação solar dos cômodos modifica-se porque eles são espelhados.

Foram entrevistadas duas pessoas por unidade com orientações solares diferentes, conforme a Figura 1. Para a Cohab Tancredo Neves, a habitação selecionada foi a mesma em que se fez a análise de desempenho através dos cálculos dos parâmetros térmicos.

Selecionaram-se usuários que permaneciam o dia todo em casa, com idades aproximadas entre 35 e 40 anos, do sexo feminino em sua maioria (apenas 1 homem), vivendo na casa há, no mínimo, três anos, gozando de boa saúde assumida e que aceitaram participar da pesquisa.

O questionário foi aplicado durante janeiro e fevereiro à tarde, período mais quente do dia (condições de verão) e julho pela manhã, período mais frio do dia, com luz solar (condições de inverno). Os entrevistados responderam oito vezes ao questionário no período de verão ( 2 vezes por semana durante quatro semanas) e oito vezes no período de inverno (quatro vezes por semana durante duas semanas), com desistências descritas nos resultados. Buscou-se, com a repetição das entrevistas, verificar a sustentação das opiniões ao longo do tempo. Procurou-se escolher dias antecedidos pelo menos por dois a três dias com comportamento semelhante, para que a resposta térmica das habitações estivesse estabilizada, a partir do acompanhamento dos dados disponibilizados pelo INMET (INSTITUTO..., 2012). A sensação térmica foi medida de acordo com a escala de sete valores do PMV (muito quente, quente, levemente quente, neutro, levemente frio, frio, muito frio) obtidos da norma ISO 7730 (INTERNATIONAL..., 1994). Durante a aplicação dos questionários, o entrevistado estava sentado em um banco sem espaldar aproximadamente no centro da sala. Ao mesmo tempo, as temperaturas interna e externa foram medidas (com o mesmo aparelho e um cabo para localizar o sensor do lado de fora da residência, protegido do sol, passando por uma janela) com um termo-higrômetro digital marca Incoterm, modelo 7666.02.0.00.

O questionário continha perguntas relativas ao número de pessoas residindo na habitação, à atividade que o entrevistado estava desempenhando antes de responder, quais cômodos considerava mais quentes e mais frios, $\mathrm{o}$ que faria para melhorar o conforto térmico de sua casa, onde costumava ficar quando sentia calor ou frio, hábitos sobre abrir e fechar janelas e portas, e se possuía algum tipo de dispositivo de resfriamento ou aquecimento, e, em caso afirmativo, onde e quando costumava acioná-lo.

Os dados foram organizados conforme intervalos de temperatura. Os resultados expressam o voto de maior frequência para o intervalo de temperatura considerado.

\section{Resultados}

Os resultados foram organizados quanto à análise de desempenho térmico e quanto à opinião dos usuários. 
Figura 1 - Habitações selecionadas no CR para aplicação de questionários

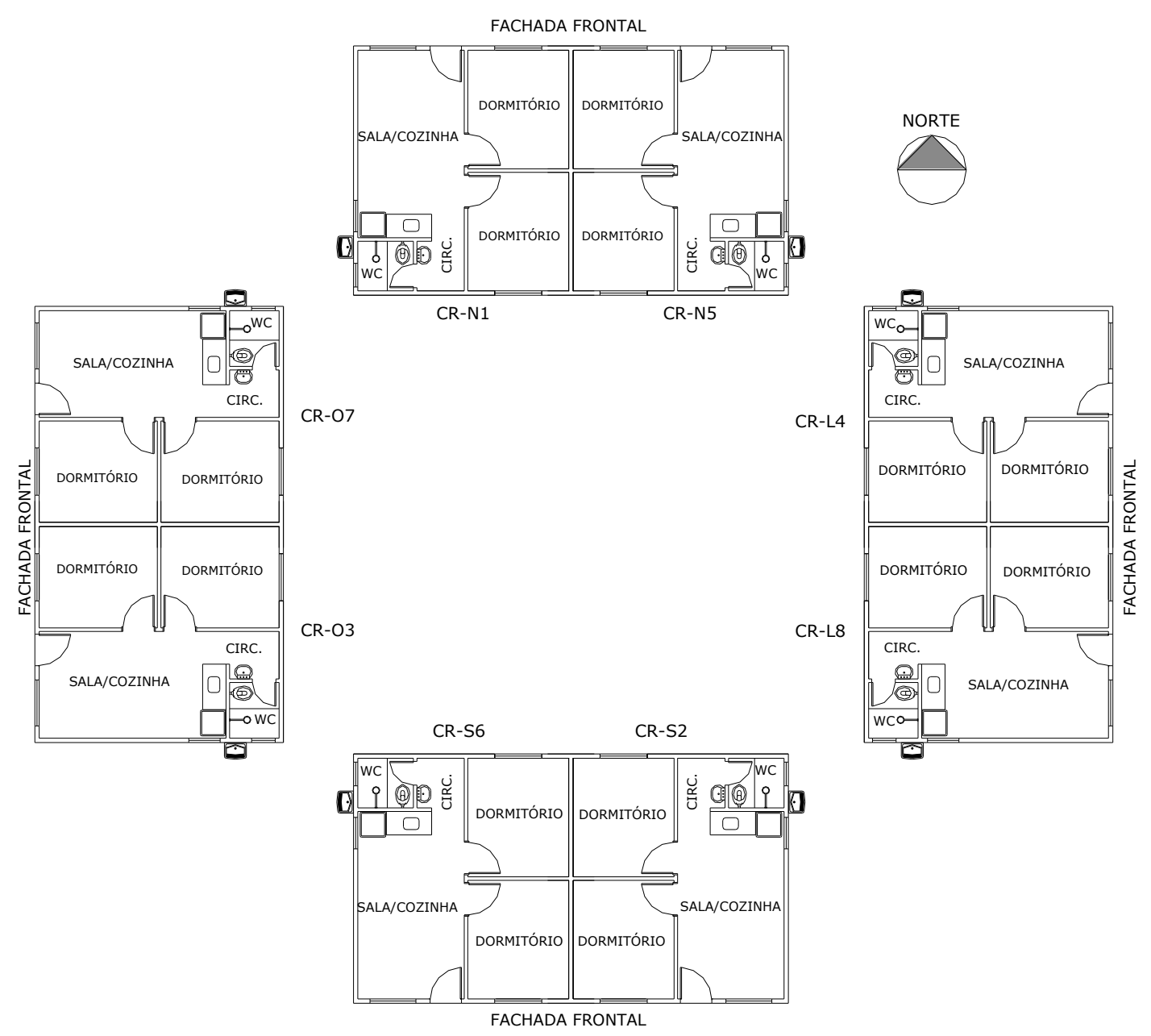

\section{Quanto à análise de desempenho térmico}

Para o CR (habitações geminadas), as unidades analisadas segundo os parâmetros térmicos foram U1, U2, U3 e U4, conforme indicado na Figura 1. Apenas uma habitação TN, com orientação da fachada principal a nordeste, foi avaliada. Para o ZA, foram avaliadas as habitações geminadas orientadas a N, S, O e L, com paredes geminadas a $\mathrm{L}, \mathrm{O}, \mathrm{N}$ e $\mathrm{S}$ respectivamente. A Tabela 1 apresenta os resultados obtidos quanto ao coeficiente $\mathrm{GV}_{\text {inverno }}$.

Para os coeficientes de perda de calor $\mathrm{GV}_{\text {inverno, }}$ o ZA apresenta melhor desempenho, resultado esperado, considerando que é uma edificação geminada, que apresenta apenas três fachadas expostas ao meio externo, o que reduz as perdas de calor no inverno, e com uma camada isolante na cobertura, reduzindo o fluxo de calor por causa desse elemento.
Apesar de o CR apresentar paredes externas com menor transmitância térmica, tem maior área de fechamento externo, em relação ao ZA, e não possui forro (perdas térmicas por frestas entre telhas cerâmicas).

A TN apresentou desempenho inferior às demais para o coeficiente volumétrico global $\mathrm{GV}_{\text {inverno }}$. Dois fatores que mais contribuíram para esse desempenho foram: alta transmitância térmica das paredes externas; e maior área de fechamentos em contato com o meio externo (isolada no lote).

A Tabela 2 apresenta resultados quanto à condensação sobre superfícies internas.

A CR apresenta menores problemas entre todas para a condensação. Há a ocorrência de condensação em todos os fechamentos exceto sobre as janelas com venezianas e paredes. Para as outras habitações, as superfícies em que não ocorre esse fenômeno são $\mathrm{o}$ forro $\mathrm{e}$ janelas com venezianas. A ocorrência de condensação é um fator relacionado diretamente com a transmitância

114 Grigoletti, G. de C.; Linck, G. I 
térmica do fechamento, isto é, quanto maior for essa propriedade térmica, maior a probabilidade de ocorrer condensação. $\mathrm{O}$ uso de fechamentos com uma transmitância térmica menor evita o surgimento de condensação e previne os possíveis danos causados à saúde com o surgimento de mofo, bolor ou umidade e a proliferação de microorganismos nocivos.

Os resultados quanto à assimetria da radiação térmica, $\Delta \mathrm{T}_{\mathrm{rp}}$, são apresentados na Tabela 3.

As coberturas simples, sem isolamento térmico, não satisfizeram o critério, demonstrando a importância desse elemento para o desempenho térmico. Maior variação entre as temperaturas radiantes planas em cada face do elemento ocorre quando a parede analisada é oeste, corroborando que essa orientação, para a latitude estudada, é desfavorável. Os resultados para as paredes na situação de inverno não apresentaram diferenças significativas de valor para diferentes orientações solares.

Os resultados para o coeficiente volumétrico $\mathrm{GV}_{\text {verão }}$ são apresentados na Tabela 4.

Os maiores ganhos de calor se dão pelas coberturas para TN e CR, resultado esperado por se tratarem de edificações térreas. Para o ZA, devido à presença da camada isolante na cobertura, as fachadas orientadas a oeste foram os elementos de maior contribuição para as orientações $\mathrm{N}, \mathrm{O}$ e L. A habitação ZA com fachada principal a sul e parede de geminação a oeste apresenta maiores ganhos térmicos pela cobertura. A tipologia $\mathrm{CR}$, para orientações $\mathrm{N}, \mathrm{O}$ e $\mathrm{L}$, apresentou $\mathrm{o}$ menor desempenho. Essa tipologia não possui forro na cobertura, sendo esse elemento importante nas trocas de calor, tanto no verão quanto no inverno, como já comentado. O ZA com fachada principal a sul e parede geminada a oeste apresenta um desempenho melhor diante das outras orientações de mesma tipologia. A TN apresentou um desempenho melhor que o CR devido a uma condição mais favorável da cobertura.

Os ganhos térmicos pelas habitações poderiam ser minimizados por meio de uso de telhas com um coeficiente de absorção menor, redução da transmitância térmica da cobertura através do acréscimo de camadas mais resistentes ou aumento de suas espessuras e possibilidade de ventilação controlada para que seja ventilada apenas durante o verão.

Comparando os resultados para CR e ZA conforme as diferentes orientações, percebe-se que a habitação com fachada frontal leste de ambos os conjuntos apresenta maior ganho de calor em relação às demais. Esse resultado pode ser devido ao fato de essas habitações não apresentarem fachada externa orientada a sul, pois é a orientação solar que menos contribui para os ganhos térmicos.

A Tabela 5 apresenta os resultados referentes ao ático ventilado no verão e não ventilado no inverno, possibilidade de ventilação noturna e aquecimento solar passivo.

Tabela 1 - Coeficientes volumétricos globais de perda de calor, GV $_{\text {inverno }}$

\begin{tabular}{|c|c|c|c|c|c|c|c|c|c|}
\hline \multirow{2}{*}{ Parâmetro térmico } & \multirow{2}{*}{$\mathbf{T N}$} & \multicolumn{4}{|c|}{$\mathbf{C R}$} & \multicolumn{4}{|c|}{$\mathbf{Z A}$} \\
\hline & & CR-N1 & CR-S2 & CR-O3 & CR-L4 & $\mathrm{N}$ & $S$ & $\mathrm{O}$ & $\mathrm{L}$ \\
\hline $\mathrm{GV}_{\text {inverno }} \mathrm{W} /\left(\mathrm{m}^{3} . \mathrm{K}\right)$ & 4,7295 & \multicolumn{4}{|c|}{3,6752} & \multicolumn{4}{|c|}{3,3830} \\
\hline
\end{tabular}

Tabela 2 - Condensação sobre superfícies internas

\begin{tabular}{c|c|c|c|c|c|c|c|c}
\hline \multirow{2}{*}{$\begin{array}{c}\text { Parâmetro } \\
\text { térmico }\end{array}$} & \multirow{2}{*}{ TN } & \multicolumn{4}{|c|}{ CR } & \multicolumn{3}{c}{ ZA } \\
\cline { 3 - 7 } Condensação? & $\begin{array}{c}\text { Sim, exceto } \\
\text { sobre venezianas } \\
\text { e forro }\end{array}$ & \multicolumn{2}{|c|}{ Sim, exceto sobre venezianas e paredes } & \multicolumn{3}{|c|}{$\begin{array}{c}\text { Sim, exceto sobre } \\
\text { venezianas e forro }\end{array}$} \\
\hline
\end{tabular}

Tabela 3 - Assimetria da radiação térmica, $\Delta T_{\mathrm{rp}}$

\begin{tabular}{c|c|c|c|c|c|c|c|c}
\hline \multirow{2}{*}{$\begin{array}{c}\text { Parâmetro } \\
\text { térmico }\end{array}$} & \multirow{2}{*}{ TN } & \multicolumn{4}{|c|}{ CR } & \multicolumn{4}{|c}{ ZA } \\
\cline { 3 - 7 } & CR-N1 & CR-S2 & CR-O3 & CR-L4 & N & S & O & L \\
\hline$\Delta \mathrm{T}_{\mathrm{rp}}$ & $\begin{array}{c}\text { Cobertura não } \\
\text { satisfaz critério }\end{array}$ & \multicolumn{2}{|c|}{ Coberturas não satisfazem critério } & \multicolumn{4}{c}{$\begin{array}{c}\text { Coberturas e paredes } \\
\text { satisfazem critério }\end{array}$} \\
\hline
\end{tabular}


Tabela 4 - Coeficiente global de ganho de calor, GV $_{\text {verão }}$

\begin{tabular}{c|c|c|c|c|c|c|c|c|c}
\hline Parâmetro & \multirow{2}{*}{ TN } & \multicolumn{4}{|c|}{ CR } & \multicolumn{4}{c}{ ZA } \\
\cline { 3 - 9 } & CR-N1 & CR-S2 & CR-O3 & CR-L4 & N & S & O & L \\
\hline $\begin{array}{c}\mathrm{GV}_{\text {verão }} \\
\mathrm{W} /\left(\mathrm{m}^{3} . \mathrm{K}\right)\end{array}$ & 19,6159 & 21,0537 & 18,8804 & 20,6498 & 21,4465 & 9,2455 & 7,1182 & 10,9691 & 11,1136 \\
\hline
\end{tabular}

Tabela 5 - Coeficiente global de ganho de calor, GV $_{\text {verão }}$

\begin{tabular}{|c|c|c|c|c|c|c|c|c|c|}
\hline \multirow{2}{*}{ Parâmetro térmico } & \multirow{2}{*}{$\mathbf{T N}$} & \multicolumn{4}{|c|}{$\mathbf{C R}$} & \multicolumn{4}{|c|}{$\mathbf{Z A}$} \\
\hline & & CR-N1 & $\mathrm{CR}-\mathrm{S} 2$ & CR-O3 & CR-L4 & $\mathbf{N}$ & $\mathbf{S}$ & $\mathbf{O}$ & $\mathbf{L}$ \\
\hline $\begin{array}{l}\text { Ático ventilado no verão e não } \\
\text { ventilado no inverno? }\end{array}$ & \multicolumn{9}{|c|}{ Não } \\
\hline Ventilação noturna? & \multicolumn{9}{|c|}{ Não } \\
\hline Aquecimento solar passivo? & Sim & Sim & Sim & Não & Não & Sim & Sim & Não & Não \\
\hline
\end{tabular}

Possibilitar a ventilação do ático no verão é uma estratégia importante para diminuir ganhos térmicos, porém esse ático deve ser não ventilado no inverno, para evitar as perdas. Esse requisito não foi satisfeito por nenhuma das habitações.

Alguns elementos poderiam ser modificados para otimizar a ventilação natural das habitações. Dispositivos de segurança, tais como grades e venezianas nas janelas das salas, permitiriam que elas ficassem abertas durante a madrugada, para captar as brisas frescas. Venezianas que propiciem menos redução na área efetiva de ventilação permitiriam o aproveitamento da ventilação noturna. $\mathrm{O}$ posicionamento das aberturas nas fachadas mais propícias para a captação de ventos de verão também contribuiria para o desempenho térmico.

Em relação à captação de radiação solar direta por janelas voltadas a norte no inverno, para as habitações geminadas CR e ZA, somente aquelas que possuem fachadas frontais voltadas a norte ou sul possuem essa possibilidade, e para a $\mathrm{TN}$, que possui todas as fachadas livres. A tipologia geminada sempre prejudicará uma das unidades quando as paredes compartilhadas forem norte ou sul. Para essa tipologia, devem ser privilegiadas fachadas frontais norte ou sul com aberturas voltadas ao norte.

As Tabelas 6 e 7 trazem os parâmetros transmitância térmica, U, fator solar, $\mathrm{FS}_{\mathrm{o}}$, e atraso térmico, $\varphi$, para as três tipologias analisadas e sua satisfação ou não dos limites recomendados pela NBR 15220 para a Zona Bioclimática 2, para paredes e coberturas respectivamente.

$\mathrm{O} \mathrm{CR}$, apesar de possuir melhor resultado para paredes, de acordo com a NBR 15220 (ABNT, 2005), apresenta a cobertura com uma solução desfavorável, o que compromete seu desempenho global, conforme visto nas Tabelas 1 e 4. O ZA, por ter uma cobertura com transmitância térmica melhor, possui menores coeficientes globais de perdas e ganhos de calor. Esse resultado indica que a cobertura é determinante para o desempenho térmico desse tipo de habitação.

\section{Quanto à opinião de usuários}

\section{Condições de verão}

No CR, cada morador foi entrevistado oito vezes, duas vezes por semana, com a exceção de dois moradores, que deixaram de responder a 1 ou 2 questionários, por problemas pessoais. Para completar as oito entrevistas, foi necessário fazer um dia a mais para alguns moradores, que não foram encontrados em casa em algum dia anterior. A pessoa selecionada na TN respondeu ao questionário apenas cinco vezes, pois precisou abandonar a pesquisa devido a problemas de saúde.

Os dias em que ocorreram as entrevistas foram 23 , 28 e 30 de janeiro e $1^{\circ}, 6,7,14,15$ e 17 de fevereiro. Os dias durante o período de análise, em geral, são semelhantes termicamente, somente apresentando temperaturas um pouco mais amenas entre os dias 11 e 12 de fevereiro, quando não ocorreram entrevistas. A menor temperatura registrada, conforme INMET, neste período foi $14,0{ }^{\circ} \mathrm{C}$, e a maior foi de $37,5^{\circ} \mathrm{C}$. O período da aplicação dos questionários caracteriza-se por amplitudes de temperatura diárias altas, com mínima registrada de $14{ }^{\circ} \mathrm{C}$ e máxima de $36{ }^{\circ} \mathrm{C}$, com umidade relativa do ar entre $40 \%$ e $85 \%$ (INSTITUTO..., 2012).

A Tabela 8 apresenta os resultados para as medições momentâneas de temperatura do ar interno, por faixas de temperatura, conforme a maioria das respostas expressas pelos entrevistados, e com o levantamento da sensação térmica percebida para condições de calor. Os usuários vestiam roupas leves de verão (chinelos de dedo, shorts e camisetas de malha). Em relação 
às normais climatológicas (30 anos entre $1961 \mathrm{e}$ 1990), o verão de 2012 foi atípico, apresentando amplitudes térmicas acima das médias de referência e umidade relativa abaixo de $40 \%$.

Os resultados indicam que o nível de satisfação térmica está aproximadamente de acordo com a faixa proposta por Givoni (1992) para países em desenvolvimento, isto é, a partir dos $28^{\circ} \mathrm{C}$ surge a sensação de quente.

Os meios comumente utilizados pelos usuários para diminuir a sensação de calor são o banho, o uso de ventiladores e o posicionamento à sombra no meio externo. Apenas dois moradores relataram não possuir ventilador. Devido às poucas condições financeiras, todas as pessoas entrevistadas relataram não apresentar outro tipo de equipamento para amenizar a sensação de calor, a não ser o ventilador, que é utilizado praticamente todos os dias, principalmente durante a tarde e a noite, períodos mais quentes do dia. A grande parte dos entrevistados relatou não conseguir ficar em casa quando sente muito calor, indicando que o interior das habitações apresenta condições de conforto mais desfavoráveis que o meio exterior, o que revela que as soluções arquitetônicas não estão adequadas ao clima da região.

Quanto à opinião sobre cômodos mais quentes no verão, foram apontados, na maioria, aqueles que possuem janelas ou paredes cegas voltadas a oeste. As unidades não permitem a captação das brisas noturnas de verão, mais frescas, que sopram de sul e sul-sudeste na região. Os cômodos menos quentes são os voltados a sul, a leste ou a norte. No entanto, devido à pequena área das habitações, à noite, o resfriamento interno, e a consequente sensação de frescor, poderia ser atingido se houvesse a possibilidade de manter a ventilação noturna abundante, o que não é possível devido à pequena área de aberturas.

Os entrevistados, com exceção da CR-O7, apontaram a cobertura como o elemento responsável pelo excesso de calor no interior da habitação, como resposta espontânea. Esse resultado demonstra a percepção dos usuários em relação à má qualidade das coberturas, de forma empírica, corroborando um comportamento esperado para edificações térreas quando a cobertura não possui resistência térmica suficiente para evitar trocas excessivas de calor.
Em relação à ventilação para as habitações do $\mathrm{CR}$, observaram-se discrepâncias entre as opiniões relatadas pelos entrevistados, inclusive para habitações com o mesmo posicionamento de aberturas em relação aos ventos. Entretanto, no geral, os moradores estavam insatisfeitos com a ventilação em suas habitações. Os cômodos apontados com uma ventilação mais eficiente são aqueles que apresentam janelas em faces diferentes, permitindo a ventilação cruzada, e aqueles que estão voltados para a fachada leste, mais favorável à captação dos ventos predominantes. Todos, por permanecerem durante o dia em casa, mantêm portas e janelas abertas, fechando-as apenas no horário de dormir.

A análise comparativa entre temperaturas registradas no interior e no exterior também demonstra a má qualidade térmica das habitações, conforme indicado na Figura 2.

Quando os dias são caracterizados por amplitudes térmicas maiores do que $15^{\circ} \mathrm{C}$, as temperaturas internas medidas no momento das entrevistas permanecem abaixo da temperatura externa medida simultaneamente, contudo acima de $29^{\circ} \mathrm{C}$, limite superior à zona de conforto. Quando as amplitudes diárias de temperatura são $10{ }^{\circ} \mathrm{C}$ ou menos, as temperaturas internas são maiores que as externas. Esse comportamento foi verificado para as cinco casas, mas CR-L4 apresentou esse comportamento por sete dias. Esta habitação apresenta fachada voltada a leste e janelas voltadas a oeste, fachada sul geminada (orientação das brisas frescas de verão), recebendo grande carga térmica durante o verão (paredes leste, oeste e norte). Para CR-S6 também foi verificado comportamento semelhante em seis dias. As unidades CR-O7 e CR-L8, com fachadas leste e oeste, apresentaram cinco dias com temperaturas interiores superiores. Já as unidades CR-N1, CRS2, CR-O3 e CR-N5 apresentaram esse comportamento por dois a três dias. CR-S2 e CRN5 possuem fachada geminada a oeste e aberturas a sul, para captar brisas frescas de verão. Comparando-se resultados apresentados na Tabela 4 e na Figura 3, verifica-se que as unidades com melhor desempenho segundo os parâmetros são as mesmas que apresentaram menor número de dias com temperaturas mais elevadas, ou seja, CR-S2 e CR-O3.

Tabela 6 - Parâmetros térmicos de acordo com NBR 15220 (ABNT, 2005), parte 3, para paredes

\begin{tabular}{c|c|c|c}
\hline Tipologia & $\mathbf{U}\left(\mathbf{W} /\left(\mathbf{m}^{\mathbf{2}} \mathbf{K}\right)\right) /$ Satisfaz? & FSo (\%)/Satisfaz? & $\varphi(\mathbf{h}) /$ Satisfaz? \\
\hline TN & $4,40 / \mathrm{Não}$ & $5,28 / \mathrm{Não}$ & $2,32 / \mathrm{Sim}$ \\
CR & 2,52/Sim & $4,04 / \mathrm{Sim}$ & $2,45 / \mathrm{Sim}$ \\
ZA & 4,14/Não & $6,63 / \mathrm{Não}$ & $2,42 / \mathrm{Sim}$ \\
\hline
\end{tabular}


Tabela 7 - Parâmetros térmicos de acordo com NBR 15220 (ABNT, 2005), parte 3, para coberturas

\begin{tabular}{c|c|c|c}
\hline Tipologia & $\mathbf{U}\left(\mathbf{W} /\left(\mathbf{m}^{2} \mathbf{K}\right)\right) /$ Satisfaz? & FSo $(\%) /$ Satisfaz? & $\varphi(\mathbf{h}) /$ Satisfaz? \\
\hline TN & $2,20 / \mathrm{Não}$ & $4,40 / \mathrm{Sim}$ & $3,56 / \mathrm{Não}$ \\
CR & $4,46 / \mathrm{Não}$ & $14,27 / \mathrm{Não}$ & $0,26 / \mathrm{Sim}$ \\
ZA & $1,16 / \mathrm{Sim}$ & $3,71 / \mathrm{Sim}$ & $1,99 / \mathrm{Sim}$ \\
\hline
\end{tabular}

Tabela 8 - Temperaturas internas e sensação térmica percebida pelos usuários

\begin{tabular}{c|c}
\hline Temperatura interna $\left({ }^{\circ} \mathbf{C}\right)$ & Sensação térmica \\
\hline $28,0-29,9$ & Levemente quente \\
$30,0-30,9$ & Quente \\
$31,0-39,0$ & Muito quente \\
\hline
\end{tabular}

Figura 2 - Temperaturas interna e externa medidas no verão
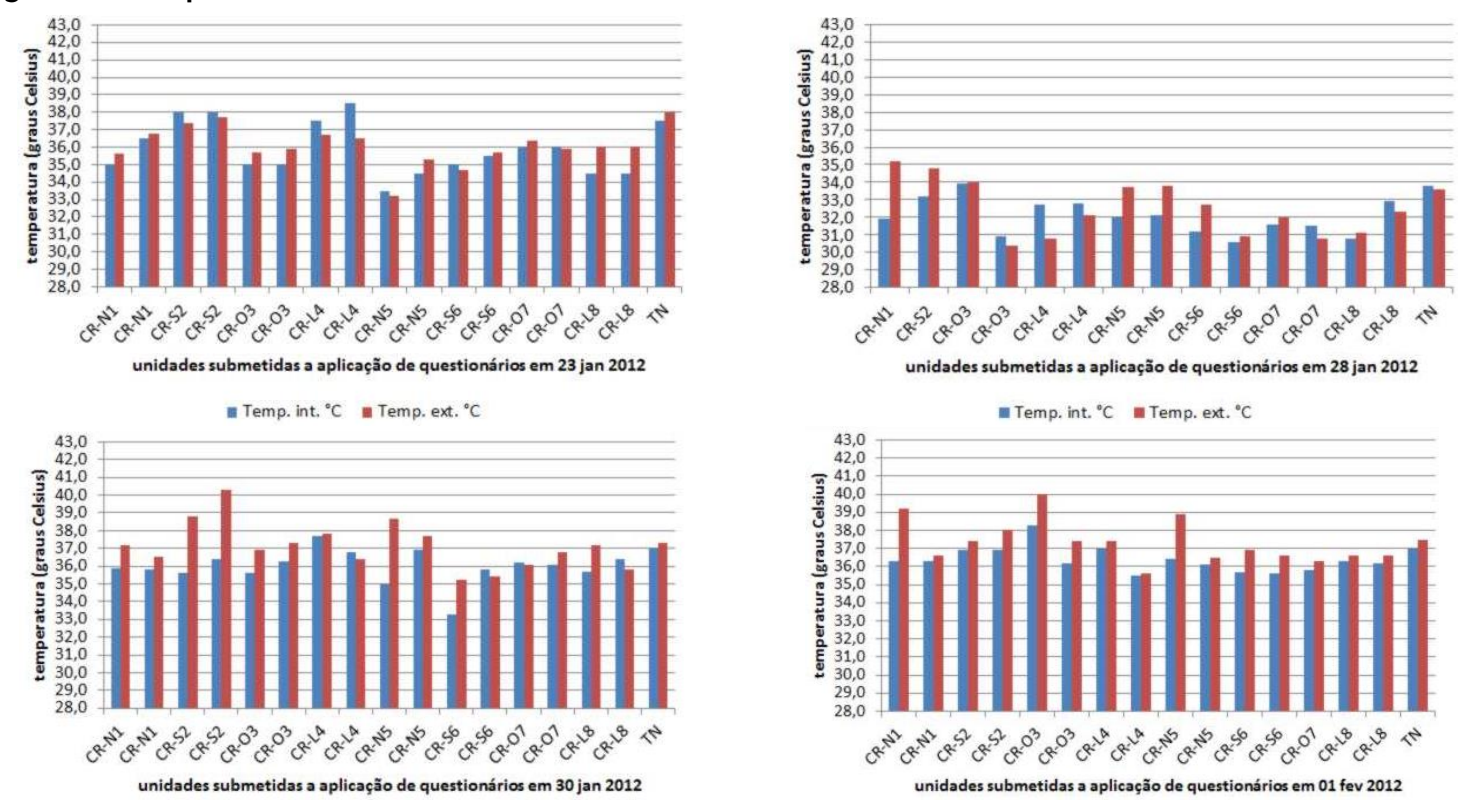

- Temp. int. ${ }^{\circ} \mathrm{C} \|$ Temp. ext. ${ }^{\circ} \mathrm{C}$
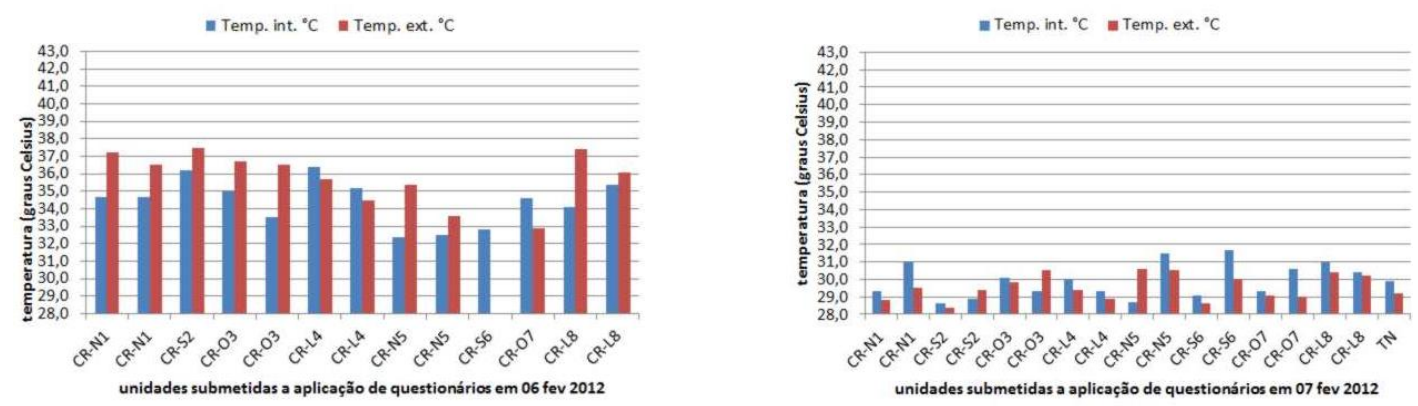

- Temp. int. ${ }^{\circ} \mathrm{C}=$ Temp. ext. ${ }^{\circ} \mathrm{C}$
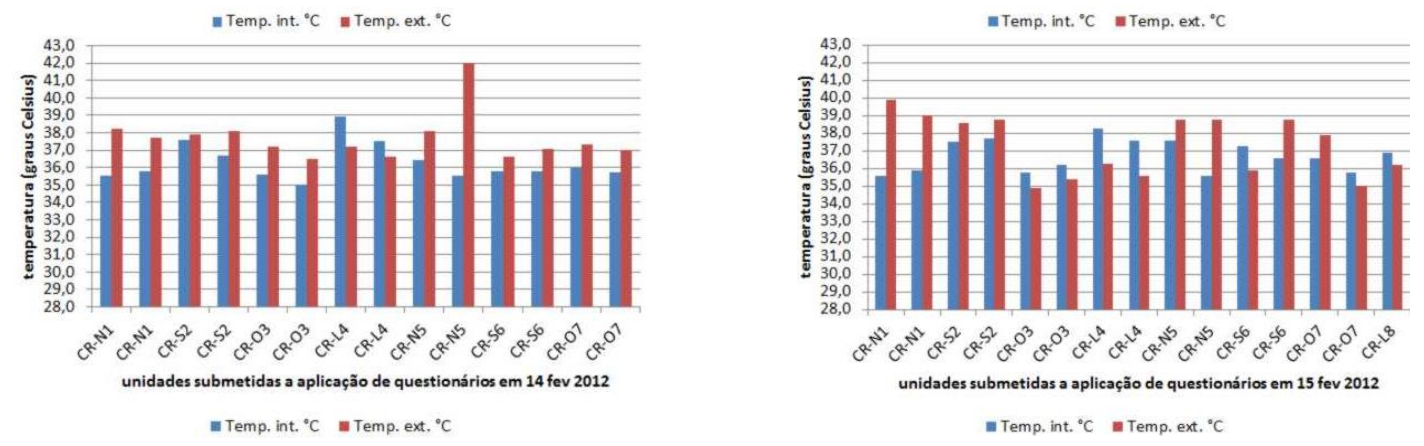

118 Grigoletti, G. de C.; Linck, G. I 
Quanto a possíveis melhorias para atingir o conforto térmico no verão, foram apontadas janelas mais amplas, bem como a colocação de forro. Esse resultado mostra que os usuários têm percepção de fatores fundamentais para o desempenho da edificação, ou seja, boa resistência para coberturas e ventilação abundante.

\section{Condições de inverno}

Durante o inverno, as entrevistas foram realizadas entre os dias 9 e 27 de julho, pela manhã. Cinco entrevistados do CR e o único entrevistado da TN desistiram de colaborar. Foram entrevistadas somente 11 pessoas no CR na etapa de inverno. Entre elas, 3 não completaram as oito entrevistas, por motivo de viagem e emprego.

O inverno de 2012 apresentou variação de temperatura significativa entre as mínimas e máximas, intercalando períodos de dias muito frios e muito quentes, em que as temperaturas inferiores aproximaram-se de $0{ }^{\circ} \mathrm{C}$, e as superiores alcançaram os $32{ }^{\circ} \mathrm{C}$, comportamento típico da região.

O período da aplicação dos questionários foi caracterizado por temperaturas inferiores a $4{ }^{\circ} \mathrm{C}$ (com $0{ }^{\circ} \mathrm{C}$ registrado em dois dias) e temperaturas máximas não acima de $20^{\circ} \mathrm{C}$, exceto nos dias $21 \mathrm{e}$ 22 de julho, com máxima registrada de $24^{\circ} \mathrm{C}$. A umidade relativa variou entre $40 \%$ e $95 \%$ (INSTITUTO..., 2012). Os usuários vestiam roupas pesadas de inverno (blusão de lã, casaco, calças compridas, sapatos fechados). Esse fato revela um hábito observado entre a população de baixa renda, de estar vestido no interior de sua casa como se estivesse no exterior, exposto ao frio.

A Tabela 9 apresenta os resultados obtidos com as medições momentâneas de temperatura do ar interno às habitações. Em relação às normais climatológicas, o inverno de 2012 apresentou temperatura mínima no período inferior às médias das mínimas registradas entre 1961 e 1990, enquanto a máxima registrada durante o período de medições foi superior à máxima histórica, sendo o inverno de 2012 considerado atípico.
Os resultados demonstram que os entrevistados possuem maior tolerância ao frio, considerando o limite inferior da zona de conforto de Givoni (1992) $\left(18^{\circ} \mathrm{C}\right)$, uma vez que o desconforto só foi apontado a partir de $11^{\circ} \mathrm{C}$ e em concordância com normas brasileiras, que indicam $12{ }^{\circ} \mathrm{C}$ como temperatura mínima admitida para HIS. O hábito de vestir-se com roupas pesadas no interior da edificação pode contribuir para esse limite mais baixo, diferentemente de populações já habituadas ao condicionamento artificial, que desejam suas casas com temperaturas internas, no inverno, similares às dos períodos mais quentes. Também, a característica do inverno no sul do Brasil pode contribuir para uma maior tolerância ao frio. Os invernos são caracterizados por ondas de calor frequentes, fazendo que os períodos contínuos de frio intenso sejam mais curtos, entremeados por períodos quentes (com temperaturas, muitas vezes, próximas aos $30^{\circ} \mathrm{C}$ ), o que torna a aceitabilidade do frio maior. Essa alternância entre períodos frios e quentes promove o aquecimento das edificações, desde que tenham inércia térmica adequada, conservando o calor para os dias mais frios.

No inverno, os moradores também preferem permanecer no exterior de suas habitações, quando há radiação solar, como forma de se manterem aquecidos. Os cômodos citados como de maior permanência quando as pessoas sentem frio são aqueles, geralmente, em que há maior incidência do sol, tornando-os mais aquecidos, ou aqueles em que está o fogão à lenha - apenas três habitações o possuem. Devido às dificuldades na obtenção de lenha, esse fogão é pouco utilizado, apenas pela manhã e à noite. Os artifícios comumente adotados pelos morados do CR para diminuir a sensação de frio são banho quente, uso de cobertores, exposição ao sol, agasalhos pesados e fogão à lenha. Apenas uma pessoa entrevistada possui aquecedor, para amenizar as temperaturas baixas no inverno e, devido às poucas condições financeiras, ele é utilizado raramente, nos quartos, somente no período da noite. Isso demonstra a importância do aquecimento solar passivo para esse tipo de habitação.

Tabela 9 - Temperaturas internas e sensação térmica apontada pelos usuários para inverno

\begin{tabular}{c|c}
\hline Temperatura interna $\left({ }^{\circ} \mathbf{C}\right)$ & Sensação térmica \\
\hline $8,0-10,9$ & Frio \\
$11,0-13,9$ & Levemente frio \\
$14,0-15,9$ & Neutro \\
\hline
\end{tabular}


Apesar de considerarem a habitação fria no inverno, a maioria dos entrevistados consegue permanecer nela quando sente frio sem utilizar qualquer equipamento para aquecê-la. Ao contrário do verão, em que as pessoas já vestem roupas leves e mantêm as janelas abertas, no inverno os moradores podem utilizar outros meios para aquecerem-se, mesmo estando dentro da habitação, como vestir roupas mais pesadas, aproveitar o sol que incide pelas janelas ou enrolar-se em cobertores. Em relação à ventilação, a maioria dos entrevistados do $\mathrm{CR}$ relatou que abre as janelas durante a manhã e à tarde, fato que pode ser negativo para aqueles que utilizam o aquecedor e o fogão à lenha, já que o calor produzido por esses equipamentos é perdido ao abrirem-se as janelas. Esse hábito está relacionado à necessidade de ventilar as habitações (para conter problemas de mofo e bolor) e também pode estar associado à área exígua disponível, que passa a sensação desagradável de clausura. Deixar portas abertas confere sensação de maior espaço. Todos os entrevistados consideraram suas casas frias no inverno e também apontaram a cobertura como o elemento que mais contribui para essa situação. Janelas e portas, devido às frestas, que promovem infiltrações indesejáveis, também foram apontadas. A má qualidade das esquadrias é um problema recorrente em HIS, como já verificado em outras pesquisas. Os cômodos apontados como mais quentes foram os voltados a sul, para habitações com fachadas principais orientadas a norte ou a sul, e para as demais, a sala e a cozinha foram consideradas os mais frios (ambientes maiores e com portas que costumam ficar abertas durante o dia).

A Figura 3 ilustra os dados de temperatura do ar interno e externo durante a aplicação dos questionários. Esses dias foram de céu claro, com exceção do dia 17 de julho, que apresentou céu de nublado a parcialmente nublado.

Das casas que possuem fogão à lenha, apenas a CR-S2 e a CR-O3 o haviam usado na noite anterior às entrevistas. A CR-S6 usou o aquecedor, nos quartos, no período da noite. Portas e janelas haviam sido mantidas fechadas entre o final da tarde até o momento das entrevistas. Todas as casas apresentaram temperaturas internas abaixo da temperatura externa em pelo menos um dia, com exceção de CR-O3, que apresentou temperaturas inferiores em ao menos três dias, mesmo fazendo uso do fogão à lenha durante a noite. CR-O3 possui a parede geminada voltada a norte, orientação para captação do sol no inverno, prejudicando a estratégia de aquecimento solar passivo. As habitações CR-N1, CR-S2 e CR-L4 (com fachadas voltadas a norte) e CR-L8 (com fachada principal voltada a leste) apresentaram temperaturas entre $10^{\circ} \mathrm{C}$ e $15^{\circ} \mathrm{C}$ para todos os dias em que ocorreram entrevistas. No entanto, a CRL8 não participou todos os dias da coleta dos dados e apresentou um desempenho considerado bom quando as demais tiveram o mesmo comportamento (com exceção do dia 12 de julho).

Quanto a possíveis ações para melhorar o conforto térmico no inverno, os usuários apontaram a colocação de forro e esquadrias de melhor qualidade, sem frestas, o que também demonstra a percepção de fatores determinantes para o desempenho da edificação na condição de inverno.

\section{Conclusões}

As principais conclusões do estudo, considerando a realidade pesquisada, são:

(a) cobertura é determinante para o desempenho das edificações, sobressaindo-se a configuração das paredes;

(b) fachada oeste, com ou sem aberturas, mais desfavorável, necessidade de prever melhor resistência térmica para esse fechamento;

(c) tipologias quando geminadas, priorizar fachadas livres a norte e sul com aberturas nas duas fachadas, para garantir ventilação cruzada;

(d) resultados obtidos a partir do coeficiente global de ganhos de calor vão ao encontro dos obtidos com medições in loco para o período do estudo;

(e) usuários submetidos às entrevistas mostraramse mais tolerantes às condições de frio;

(f) importância de esquadrias com ausência de frestas para impedir perdas no inverno e com sistemas de segurança e privacidade que permitam ampla ventilação noturna no verão; e

(g) as HIS demonstraram, pelos dois métodos de análise, baixo desempenho térmico tanto no verão quanto no inverno.

Além da configuração da edificação em si, é importante que os projetos urbanos para HIS incluam vegetação urbana que sombreie superfícies pavimentadas externas (como ruas e calçadas), de forma a reduzir a temperatura do ar que é captada para o interior das habitações, o que colaborará para um melhor conforto térmico dos usuários. 
Figura 3 - Temperaturas interna e externa medidas no inverno
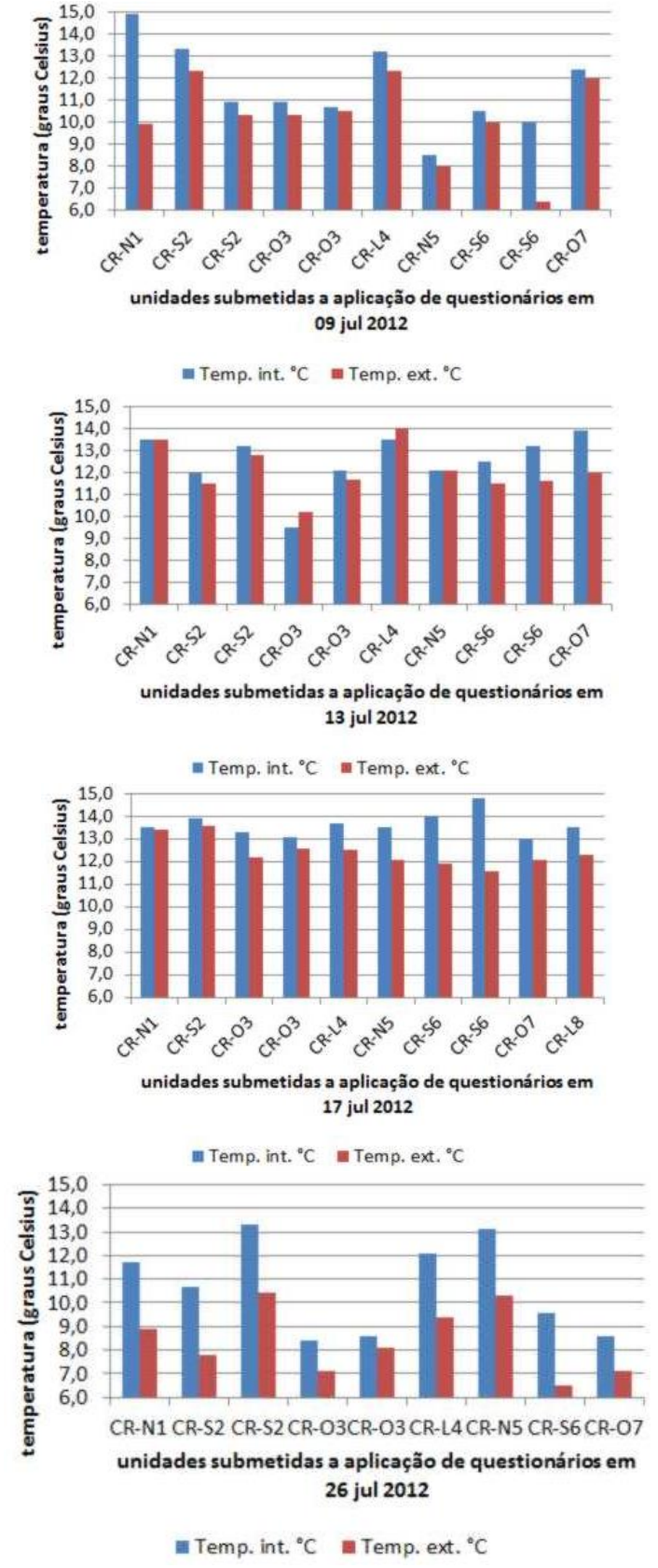

Os resultados desta pesquisa são contextualizados para a Zona Bioclimática 2 e para a realidade sociocultural específica da população de baixa renda de Santa Maria, no RS. A principal limitação da pesquisa diz respeito ao levantamento da percepção dos usuários, sendo necessário ampliar o número de participantes para fortalecer os resultados encontrados. A principal dificuldade está na motivação dos usuários para que concordem em responder aos questionários.
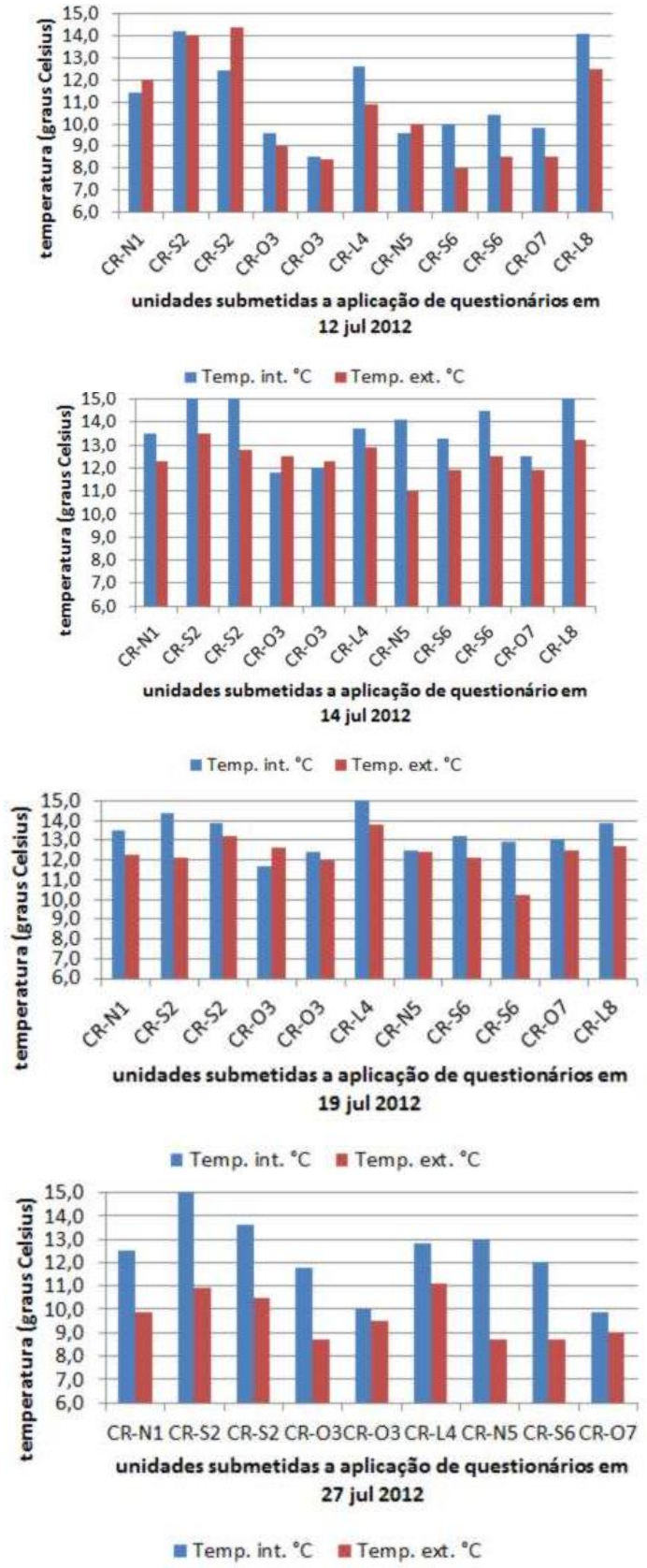

\section{Referências}

AMERICAN SOCIETY OF HEATING, REFRIGERATING AND AIR CONDITIONING ENGINEERS. Standard 55: thermal environmental conditions for human occupancy. Atlanta, 2004.

ASSOCIAÇÃO BRASILEIRA DE NORMAS TÉCNICAS. NBR 15575: edificações habitacionais: desempenho. Rio de Janeiro, 2013.

ASSOCIAÇÃO BRASILEIRA DE NORMAS TÉCNICAS. NBR 15220: desempenho térmico de edificações. Rio de Janeiro, 2005. 
AROZTEGUI, J. M.; BRIZOLARA, A. Abordagem do Estabelecimento de Exigências de Desempenho Térmico das Paredes Feitas de Concreto de Diversos Tipos, Quando Aplicadas à Habitação Popular. Porto Alegre: UFRGS, 1980. Caderno Técnico do Programa de PósGraduação em Engenharia Civil.

GIVONI, B. Comfort, Climate Analysis and Building Design Guidelines. Energy and Buildings, v. 18, n. 1, p. 11-23, 1992.

GIVONI, B. Man, Climate and Architecture. London: Applied Science, 1981.

GOMES, C. H. de G. Análise dos Níveis de Conforto Térmico em Um Edifício de Escritórios na Cidade de Maringá. Florianópolis, 2003. 129 f. Dissertação (Mestrado em Engenharia Civil) - Escola de Engenharia, Universidade Federal de Santa Catarina, Florianópolis, 2003.

GOMEZ, C. G. et al. Sensación Térmica Percibida en Vivienda Económica y Auto-Producida, en Periodo Cálido, Para Clima Cálido Húmedo. Ambiente Construído, Porto Alegre, v. 11, n. 4, p. 99-111, out./dez. 2011.

GRIGOLETTI, G.; ROTTA, R.; MÜLLER, S. Thermal Performance Envalutation of Four Low Income Houses in Santa Maria - Brazil. In: PASSIVE AND LOW ENERGY

ARCHITECTURE, 27., Louvain-la-Neuve, 2011. Proceedings... Louvain-la-Neuve: PLEA, 2011.

GRIGOLETTI, G. de C.; SATTLER, M. A. Método de Avaliação Global de Desempenho Higrotérmico de Habitações de Interesse Social Para Porto Alegre - RS - Brasil. Ambiente Construído, Porto Alegre, v. 10, n. 2, p. 101-114, abr./jun. 2010.

INSTITUTO NACIONAL DE METEOROLOGIA. Dados em gráficos: estações automáticas. Estação A803 - Santa Maria. Disponível em: <http://www.inmet.gov.br/portal/index.php?r=hom e/page\&page=rede_estacoes_auto_graf $>$ Acesso em: 15 out. 2012.
INTERNATIONAL ORGANIZATION FOR STANDARDIZATION. ISO 7726: ergonomics of the thermal environment: instruments for measuring physical quantities. Genève, 1996.

INTERNATIONAL ORGANIZATION FOR STANDARDIZATION. ISO 7730: moderate thermal environments: determination of the PMV and PPD indices and specification of the conditions for thermal comfort. Genève, 1994.

KRÜGER, E. L.; DUMKE, E. M. S. Avaliação Integrada da Vila Tecnológica de Curitiba. Ciência e Cultura, Tuiuti, v. 25, p. 63-82, 2001.

LÓPEZ, C. et al. Human Adaptative Ability in Social Welfare Housing in Response to Environmental Conditions of a Space. In: PASSIVE AND LOW ENERGY ARCHITECTURE, 28., Lima, 2012. Proceedings... Lima: PLEA, 2012.

MERCADO, M. V.; ESTEVES, A.; FILLIPÍN, C. Comportamiento Termico-Energético de Una Vivienda Social de la Ciudad de Mendonza, Argentina. Ambiente Construído, Porto Alegre, v. 10, n. 2, p. 87-100, abr./jun. 2010.

RABELO, P.; TAFRA, S.; PALMA, J. Analysis of Environmental Performance in a Social Housing: housing complex at Conchalí, Santiago of Chile. In: PASSIVE AND LOW ENERGY ARCHITECTURE, 28., , Lima, 2012. Proceedings... Lima: PLEA, 2012.

SACHT, H. M.; ROSSIGNOLO, J. A. Avaliação do Conforto Térmico de Habitações Térreas de Interesse Social Com Vedações em Alvenaria de Blocos de Concreto e Cerâmicos. In: ENCONTRO NACIONAL DE TECNOLOGIA NO AMBIENTE CONSTRUÍDO, 12., Fortaleza, 2008. Anais... Fortaleza: ANTAC, 2008.

\section{Agradecimentos}

Ao $\mathrm{CNPq}$, pelo apoio financeiro na forma de concessão de bolsa de estudo. 


\section{Giane de Campos Grigoletti}

Departamento de Arquitetura e Urbanismo, Centro de Tecnologia | Universidade Federal de Santa Maria | RS590 km 8, Prédio 30, sala 204, Camobi | Santa Maria - RS - Brasil | CEP 97105-900 | Tel.: (55) 220-8771 | E-mail: grigoletti@smail.ufsm.br

\section{Gabriela Inês Linck}

Departamento de Arquitetura e Urbanismo, Centro de Tecnologia | Universidade Federal de Santa Maria | Tel.: (55) 220-8772 |

E-mail: gabrielalinck@gmail.com

\section{Revista Ambiente Construído}

Associação Nacional de Tecnologia do Ambiente Construído

Av. Osvaldo Aranha, $99-3^{\circ}$ andar, Centro

Porto Alegre - RS - Brasil

$$
\text { CEP } 90035-190
$$

Telefone: +55 (51) 3308-4084

Fax: +55 (51) 3308-4054

www.seer.ufrgs.br/ambienteconstruido

E-mail: ambienteconstruido@ufrgs.br 